\title{
Increased Drought and Pluvial Risk over California due to Changing Oceanic Conditions ${ }^{\mathfrak{O}}$
}

\author{
JONGHUN KAM \\ Department of Civil and Environmental Engineering, Princeton University, Princeton, New Jersey \\ JUSTIN SHEFFIELD \\ Department of Civil and Environmental Engineering, Princeton University, Princeton, New Jersey, \\ and Geography and Environment, University of Southampton, Southampton, United Kingdom
}

(Manuscript received 10 December 2015, in final form 18 August 2016)

\begin{abstract}
This study evaluates wintertime drought and pluvial risk over California through a Bayesian analysis of the upper and lower quartile of PRISM-based precipitation from 1901 to 2015. Risk is evaluated for different time windows to estimate the impact of interannual and decadal-to-multidecadal Pacific and Atlantic variability [positive and negative phases of ENSO, Pacific decadal oscillation (PDO), and Atlantic multidecadal oscillation (AMO)]. The impact of increasing trends in global sea surface temperature (SST) on drought and pluvial risk is also examined with idealized experimental runs from three climate models [GFDL Atmospheric Model version 2.1 (AM2.1), CCM3, and GFS]. The results show that the influence of oceanic conditions on drought risk in California is significant but has changed with higher risk in the last half century, especially in Southern California. The influence of oceanic conditions on pluvial risk has also been significant, especially during the warm phase of the Pacific Ocean, but increases over the last century are small compared to drought. Results from the idealized climate model experiments show that natural variability likely played a major role in the observed changes in risk, with the global SST increasing trend possibly tempering the increases regionally but not significantly over California. Despite evolving preferential oceanic conditions for a pluvial event during the 2015/16 winter (positive phase of ENSO and PDO), California received an $11 \%$ winter precipitation surplus, which was not sufficient for drought recovery. The seasonal and longer-term outlook for negative phases of ENSO and PDO implies that drought risk will be elevated in Southern California for the next decade.
\end{abstract}

\section{Introduction}

California is one of the most vulnerable states in the United States to severe drought because of the large and growing water demand for irrigation, energy production, and recreation, as well as the limited water supply from the relatively dry regional climate (Grantham and Viers 2014). The current drought that has persisted since 2011 has led to a declaration of a drought state of emergency

Supplemental information related to this paper is available at the Journals Online website: http://dx.doi.org/10.1175/ JCLI-D-15-0879.s1.

Corresponding author address: Dr. Jonghun Kam, Atmospheric and Oceanic Sciences Program, Princeton University, 201 Forrestal Rd., Princeton, NJ 08540.

E-mail: jkam@princeton.edu and mandatory curtailment of municipal and agricultural water use (Seager et al. 2015). Most of California's precipitation falls in the wintertime, and the current drought has been driven by reductions in precipitation over the past winters (Mao et al. 2015). The data record (Daly et al. 2008) shows record-breaking deficits in December 2013 and January 2014 relative to the past century, moderate deficits in February 2014, and significant total winter precipitation deficits (less than 25th percentile) during 2013/ 14 winter (Fig. 1c). Most of California (67\% of the state) experienced some form of severe drought (below 25th percentile) during the winters of 2011-14. The drought was also compounded by the more moderate impact of warming-induced declines in snowpack and earlier snowmelt, which has affected the state water supply and water temperatures in the following seasons (Barnett et al. 2008). Snowfall in the Sierra Nevada in mid-February 2015 was the lowest since 1951 (Mao et al. 2015; Pan et al. 2003) 
(a) SWE Percentiles for Feb. 192015

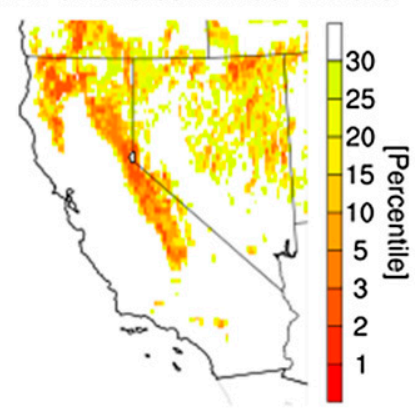

(b) CA Water Thickness Anomalies (2002-2015)

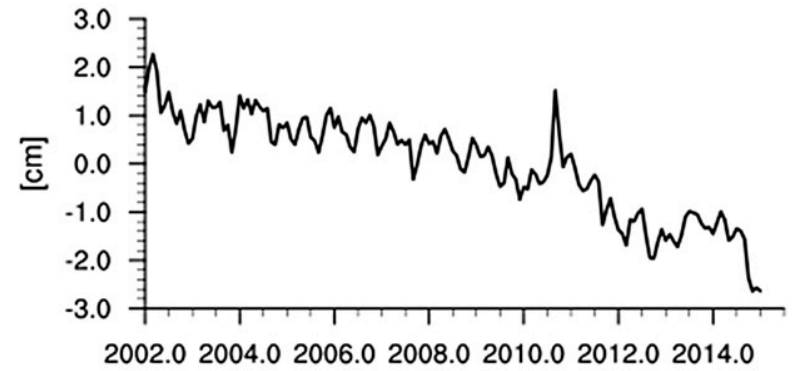

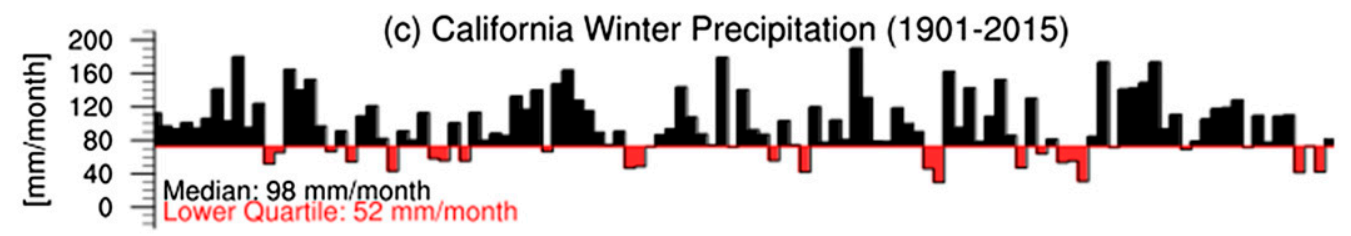

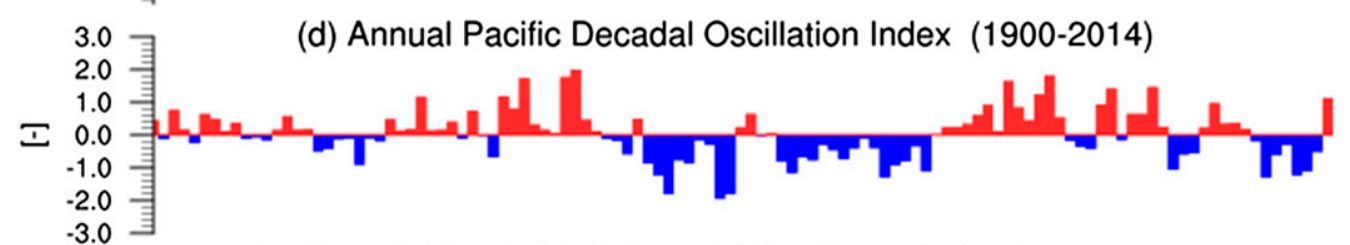

(e) Annual Atlantic Multi-Decadal Oscillation Index (1900-2014)
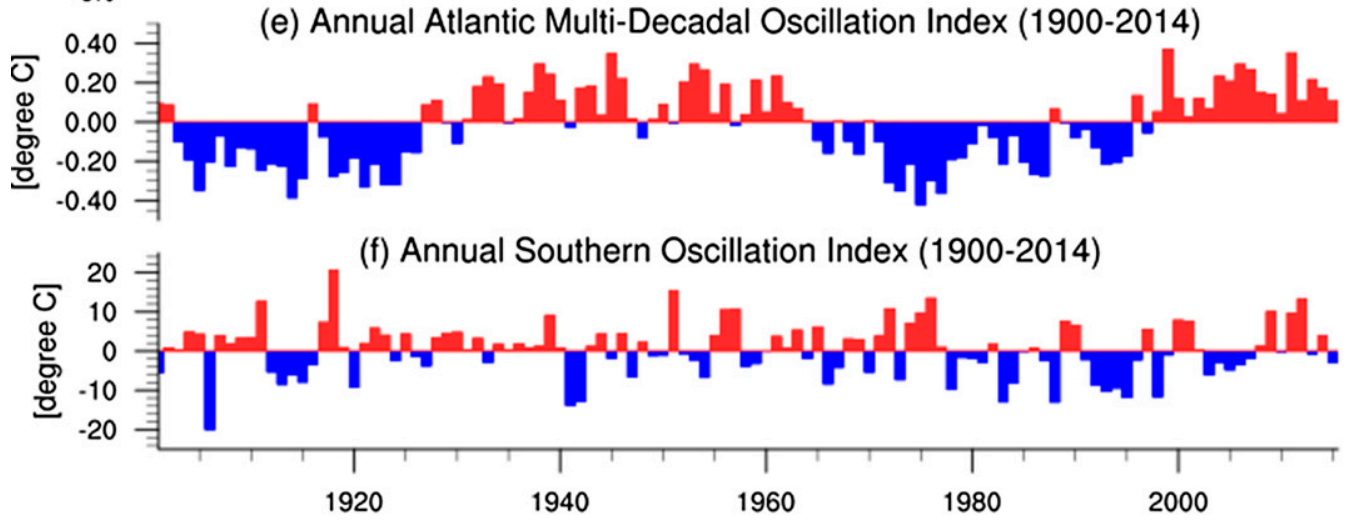

FIG. 1. The severity of 2014/15 California drought. (a) Simulated snow water equivalent percentile is simulated from the Variable Infiltration Capacity (VIC) land surface hydrologic model. The percentile is computed with respect to the samples within a 49-day window in 1951-2004. (b) Time series of water thickness anomalies over May 2002 through April 2015 from the GRACE data, which are based on climatology for 2004-08. The GRACE data show the deficit of water storage is about $-4.0 \mathrm{~cm}$ on 1 November 2013 [the water storage deficit in November based on climatology (2004-08) is $-2.0 \mathrm{~cm}$ ]. Time series of (c) winter precipitation, (d) annual PDO index, (e) AMO index, and (f) SOI over 1900-2014. The median of wintertime precipitation is shown in (c). The positive phase of the SOI represents a phase of ENSO (La Niña).

and below the 10th percentile at the end of February 2015 (Fig. 1a). These deficits led to reduced groundwater recharge, and when combined with continued groundwater pumping, especially in the highly productive agricultural region of the Central Valley (Fig. 1b), drove groundwater depletion of about $2 \mathrm{~mm} \mathrm{yr}^{-1}$ (about $70 \%$ of the regional total water loss) since 2003 (Famiglietti et al. 2011). Precipitation during the last winter (2014/15) was slightly above the 25th percentile but was not enough for drought recovery.
Although the current drought is exceptional in terms of its impacts, there have been multiple severe and often lengthy droughts over the last century and before. These include the severe but short winter drought of 1976/77 (Namias 1978) and longer-term dry conditions during 1987-92 (Dixon et al. 1996). Prior to the instrumental record, paleoclimate data indicate that the region has experienced droughts that dwarf anything experienced during the past century, including "megadroughts" during the medieval period (Stine 1994; Cook et al. 2014). 
The physical mechanisms that lead to drought for the region are complex (Namias 1978; Schubert et al. 2004) and are complicated further by the potential influence of climate change (Seager et al. 2007) that may be changing the risk of drought. About $45 \%$ of California's annual precipitation occurs in winter and originates mainly from advected moisture via westerly winds over the extratropical Pacific Ocean (Gimeno et al. 2012). In turn, this is driven by variations in the Pacific, as characterized by El Niño-Southern Oscillation (ENSO; Schonher and Nicholson 1989) and the Pacific decadal oscillation (PDO; McCabe et al. 2004), and modulated by conditions in the North Atlantic depending on the season, shifting the location of the North American jet and the position and strength of the wave train (Mo et al. 2009). Several studies have shown an influence of global warming on California winter precipitation across spatial scales. At the planetary scale, the current California drought has been influenced by a reduction in North Pacific storms resulting from the presence of upper-level high pressure anomalies over the eastern North Pacific (Bond et al. 2015). These in turn have been linked to the recordbreaking warm sea surface temperature anomalies over that region in 2014, the risk of which has been estimated to be amplified about 2 times by anthropogenic impacts (Kam et al. 2015). On the other hand global warming has been implicated in the increase in the risk of pluvials over California (Wang and Schubert 2014) due to increases in atmospheric humidity over the eastern North Pacific. The current drought has also been linked to the recent global warming hiatus (Delworth et al. 2015).

This study is designed to understand the influence of oceanic conditions on drought and pluvial risk over California for different time windows from observational data and to evaluate the impact of global sea surface warming trends on risk. To meet this purpose, this study uses a Bayesian approach to compute drought and pluvial risk during the full period and during positive and negative phases of the PDO, Atlantic multidecadal oscillation (AMO), and ENSO. We also use data from idealized experimental runs from three global climate models [GFDL Atmospheric Model version 2.1 (AM2.1), NCAR Community Climate Model version 3 (CCM3), and NCEP Global Forecast System (GFS)]. Detailed descriptions of the data and methods are presented in section 2 . Section 3 shows the resulting drought and pluvial risk maps over California from the observational data, as well as the GCM-simulated precipitation deficit and surplus forced by prescribed SST anomaly patterns with and without SST trends. Section 4 highlights the findings of this study and provides an outlook for California drought and pluvial risk.

\section{Data and methods}

The annual PDO index, AMO index, and Southern Oscillation index (SOI) for 1900-2014 were computed from monthly indices from the University of Washington, NOAA/Earth System Research Laboratory, and the Australian Bureau of Meteorology, respectively. The SOI is opposite in sign compared to ENSO. Wintertime precipitation values over California for 1901-2015 were computed from monthly precipitation data from the Parameter-Elevation Regressions on Independent Slopes Model (PRISM) with 4-km spatial resolution (www.prism.oregonstate. edu; Daly et al. 2008). We computed composites of sea surface temperature (SST) anomalies for 1900-2014 using the Hadley Centre Sea Ice and Sea Surface Temperature dataset (HadISST; Rayner et al. 2003). These datasets are generated based on physically consistent methods and models. However, because of the sparsity of observational data in the earlier part of the study period, the HadISST data have larger uncertainties (Rayner et al. 2003). The PRISM data use observed precipitation records from the California Data Exchange Center (CDEC) stations that have relatively good coverage over the state since the early 1900s (Daly et al. 2008). Anomalies of wintertime vertically integrated moisture fluxes and geopotential heights at $500 \mathrm{hPa}$ were calculated for 1901-2012 from the Twentieth Century Reanalysis version 2 (20CRv2; Compo et al. 2011). The $20 \mathrm{CRv} 2$ data are based on assimilation of surface pressure measurements and are also more uncertain during the early period because of the smaller number of observations. We compute the mean component of moisture fluxes from a product of monthly mean wind and specific humidity for the composite analysis during the positive and/or negative phases of the PDO and ENSO for the first and last 80 years of the record. The long-term average of the moisture fluxes is mostly driven by the mean direction and magnitude of moisture transport, while the transient eddies play a major role in moisture transport in extreme years (Kam et al. 2014a). However, as the 20CR project currently provides only monthly specific humidity and winds, we are unable to estimate the total moisture transport and convergences (mean plus transient eddies). The results in section $3 \mathrm{~b}$ are therefore unable to distinguish the role of transient transport and convergences to California droughts and pluvials. To evaluate the robustness of the 20CRv2 data, we compared regionally averaged wintertime precipitation from the $20 \mathrm{CRv} 2$ 
and PRISM datasets (temporal correlation coefficient is greater than 0.95; see Fig. S1 in the supplementary material).

We calculate the uncertainty of our estimates in event frequency $p$ within a Bayesian framework. We choose a threshold value as the lower quartile (the 25th percentile) of California wintertime precipitation over 1901-2015 at each grid cell. For pluvials we use the upper quartile (the 75 th percentile). We transform the time series of winter precipitation to a Bernoulli process, a series of zeros (no occurrence) and ones (drought or pluvial occurrences). Based on the threshold value, the expected drought or pluvial frequency $\bar{p}$ is 0.25 . We can compute the posterior distribution for event frequency $p$ (the unknown parameter) given a Bernoulli process sample. First, we computed the lag- 1 autocorrelation of time series of the Bernoulli process to evaluate whether drought or pluvial years are correlated, following Damsleth and El-Shaarawi (1988). For drought and pluvial events, only one percent of the area of California shows significant autocorrelation (not shown). According to Bayesian inference theory, the posterior distribution is another beta distribution with different parameter values given the prior distribution is a uniform distribution (a beta distribution with $\alpha=1$ and $\beta=1$ ). The posterior distributions for the full period and the positive and negative phases of PDO, AMO, and ENSO are derived from the fitted beta distributions that have different $\alpha$ parameters [total number of years $s$ minus the number of drought occurrences $n$ plus one $(s-n+1)]$ and different $\beta$ parameters $(n+1)$ during the given periods. This method follows the study of Kam et al. (2014b), who focused on drought risk over the continental United States. Here, we focus on California winter meteorological drought and pluvial risk. We test the sensitivity of the impact of oceanic states on drought and pluvial risk using different moving window sizes (see Fig. S2 in the supplementary material). The first and last 60 years are essentially independent (ignoring temporal persistence), but they are more sensitive to drought and pluvial events because of the relatively small window size.

To understand the impacts of global warming on drought and pluvial risk over California, we used three GCM idealized experiment runs from the CLIVAR Drought Working Group initiative (Findell and Delworth 2010): GFDL AM2.1, CCM3, and GFS. Individual experiment runs were forced with prescribed idealized SST anomalies for 50 years for the GFDL AM2.1 and CCM3 and for 36 years for the GFS model, which provides larger sample sizes for combinations of the cold phase of the Pacific and the warm phase of the
Atlantic than from the observational data. For example, there are only 16 years with the co-occurrence of the negative phase of the PDO $[\mathrm{PDO}(-)]$, positive phase of the $\mathrm{AMO}[\mathrm{AMO}(+)]$, and negative phase of ENSO [ENSO (-)] from HadISST data (1900-2014). The prescribed SST patterns in the idealized experimental runs are taken from the first three modes of a rotated principal component analysis (Schubert et al. 2009). The first mode is a linear trend of global sea surface temperature, the second mode is interannual and decadal variability of the Pacific, and the third mode is decadal variability of the Atlantic. Drought (pluvial) is defined as the 25th (75th) percentile of winter precipitation from the GCM runs forced with cold (warm) Pacific and warm (cold) Atlantic SST anomalies without global SST increasing trend. Second, with this threshold value, we compute the posterior distributions from the fitted beta distribution functions from the GCM experiments forced with the idealized SSTs plus global SST increasing trend. This enables us to quantify changes in drought and pluvial risk due to the increasing trend of SST as depicted by the models.

\section{Results}

\section{a. The changing influence of oceanic states on California drought and pluvial risk}

Our results indicate that over California a strong negative phase of the PDO has historically increased the expected drought frequency by more than $5 \%$ (frequency of 0.3 ; return period of about $3 \mathrm{yr}$ ) while a strong positive phase decreased it by $5 \%$. The cool La Niña phase of ENSO increased the expected drought frequency over Southern California by more than $5 \%$ regardless of its strength; however, strong positive events (El Niño) decreased drought frequency over all California by $10 \%$ (frequency of 0.15 ; return period of about 6 yr; Figs. 2d,e). The AMO, by itself, plays a minor role in California wintertime drought. These oceanic influences have likely played a role in the recent California drought. During the winters of 2011/12 and 2012/ 13, the cool La Niña phase of ENSO persisted, and the cold phase of the PDO and the warm phase of the AMO persisted during the winter of 2011/12 through the fall of 2013, which led to winter precipitation deficits below the 25th percentile during these winters. Since February 2014, the PDO, AMO, and ENSO have been in transition, with precipitation slightly more than the 25 th percentile during the winter of 2014/15.

We find that in recent decades, the influence of SSTs on California drought has changed. During the last 80 years (1936-2015), the negative phases of ENSO and PDO are associated with an elevation of the risk of 

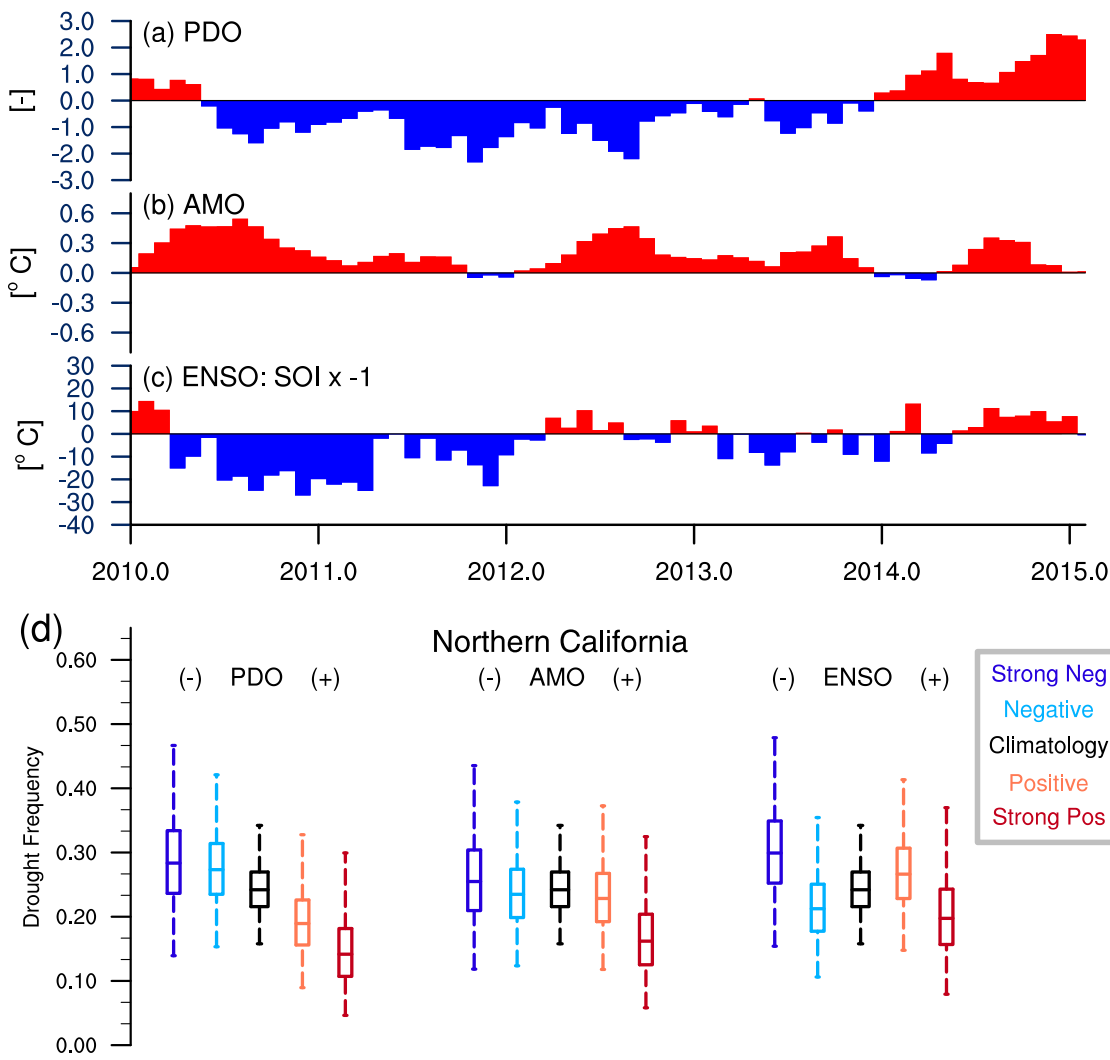

\section{Northern California}
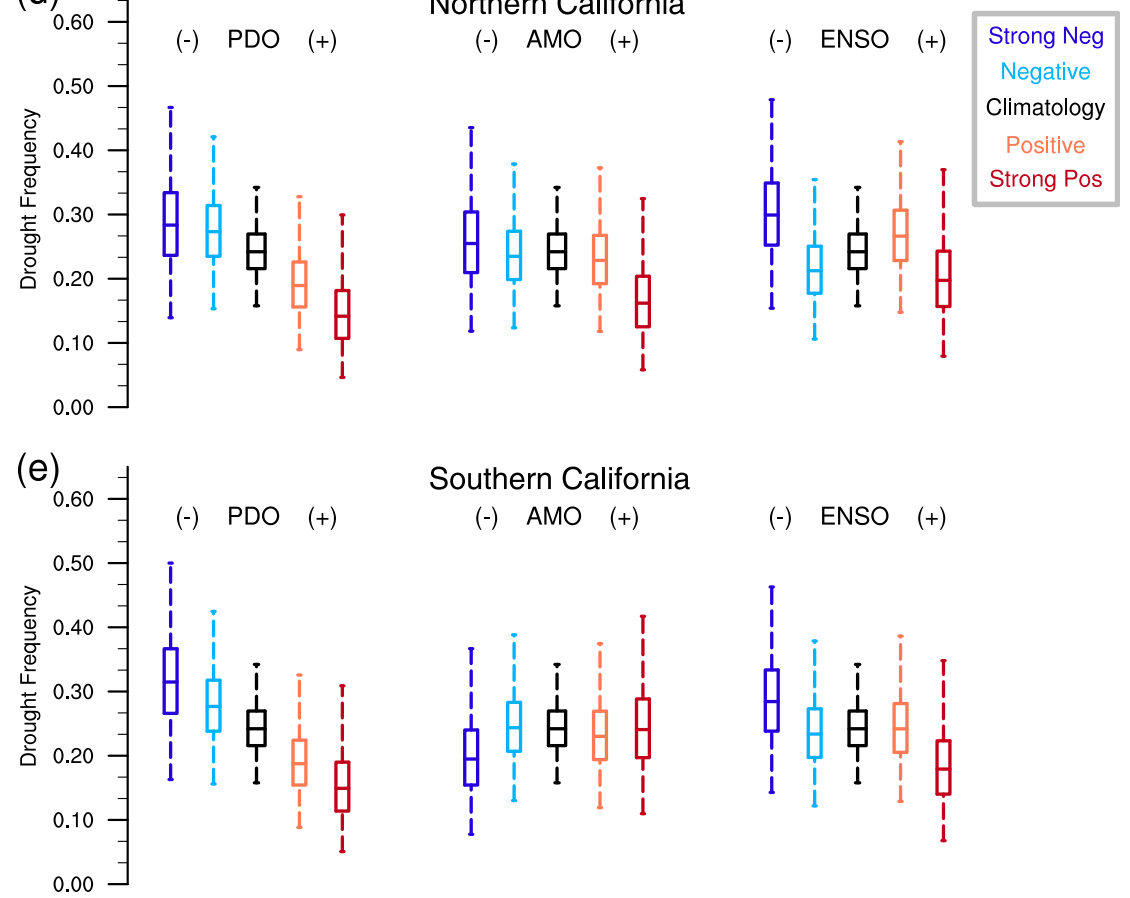

FIG. 2. Favorable oceanic conditions for California drought. Time series of the monthly (a) PDO, (b) AMO, and (c) ENSO indices from January 2011 through February 2015. (d),(e) The conditional distributions are computed from the regional averages of drought occurrences during certain times: strong negative (blue; below the 33rd percentiles), negative (cyan; below the median), climatology (black; 1900-2014), positive (orange; above the median), and strong positive (red; above the 66th percentiles) of the annual PDO, AMO, and ENSO indices, respectively. The bottom and top sides of the box represents the accumulated belief of degree at $25 \%$ and $75 \%$ from the inverse posterior distribution functions, and the line within the box represents the accumulated belief of degree at $50 \%$ from the inverse posterior distribution functions. Whiskers represent the accumulated belief of degree at $1 \%$ and $99 \%$ from the inverse posterior distribution functions. Northern and Southern California are defined as California above and below $37.5^{\circ} \mathrm{N}$.

drought for $40 \%$ and $32 \%$ of the area of California, respectively, with the degree of belief $\geq 0.9$ (green shaded areas in Fig. 3), while less than 5\% of the area of California showed elevated drought risk during these phases of ENSO and PDO over the first 80 winters (1901-80). In contrast, there has been no significant change in overall drought risk, irrespective of oceanic states. The positive phase of the AMO elevated the risk 

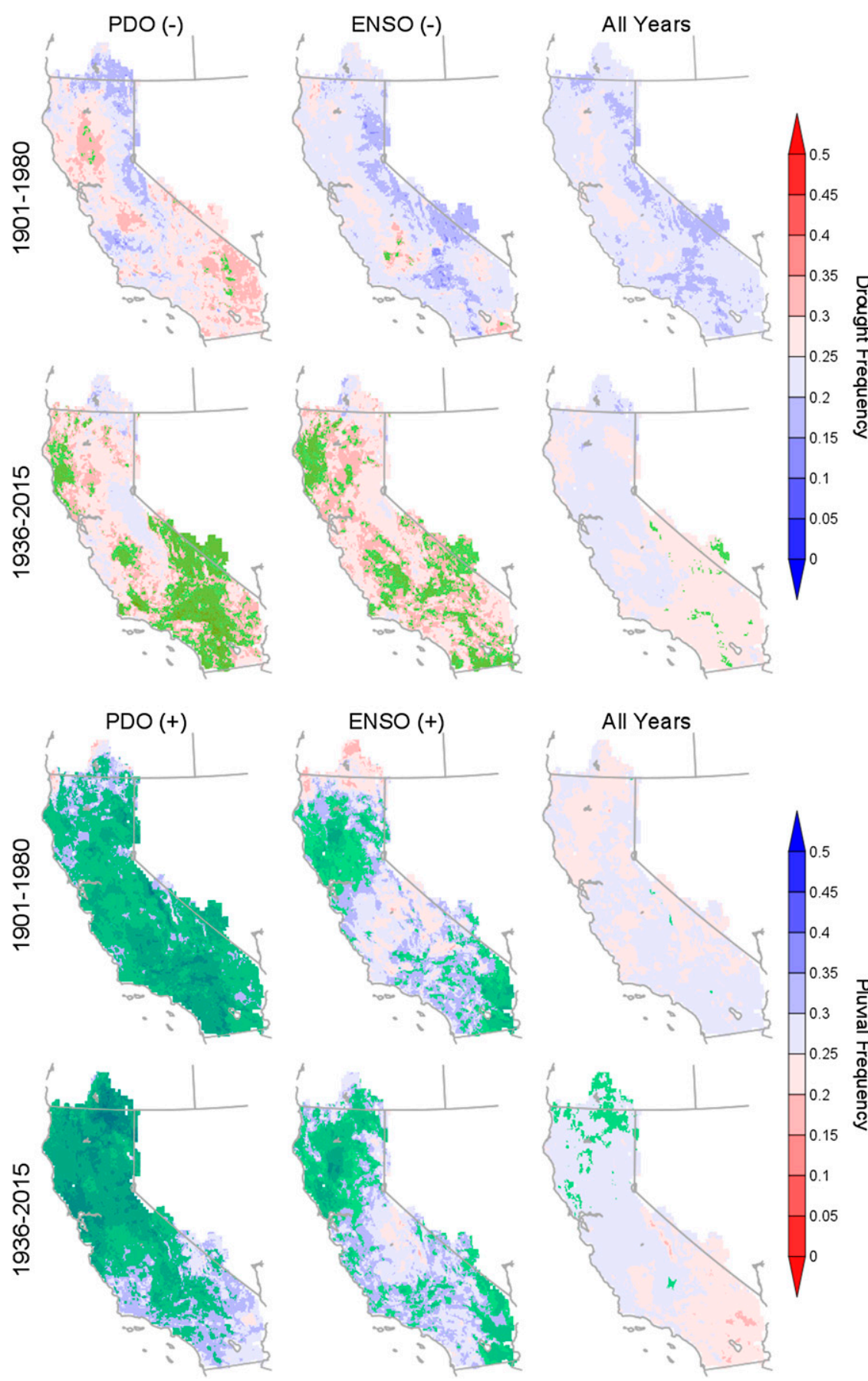

FIG. 3. Multidecadal changes in the Pacific Ocean with California winter drought and pluvial risk. (top) Drought frequency maps during the negative phases of the (left) PDO and (center) ENSO indices of the periods 1901-80 and 1936-2015. (bottom) Pluvial frequency maps during the positive phases of the (left) PDO and (center) ENSO indices of the periods 1901-80 and 1936-2015. (right) To address the trends in drought and pluvial risk, (top) drought and (bottom) pluvial frequency maps during the first and last 80-yr periods (1901-80 and 1936-2015, respectively) are shown. Green shaded areas over blue (red) shaded areas represent the area with the uncertainty equal to or greater than the degree of belief (DB) equal to or greater than $90 \%$, to have higher drought and pluvial frequency than $0.25[\mathrm{DB} \geq 0.9(\bar{p} \geq 0.25)]$ based on the conditional posterior distributions. 
(a) PDO (-)

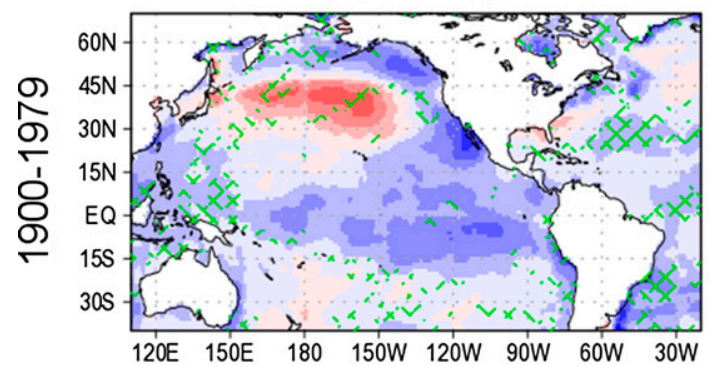

(c) PDO (-)

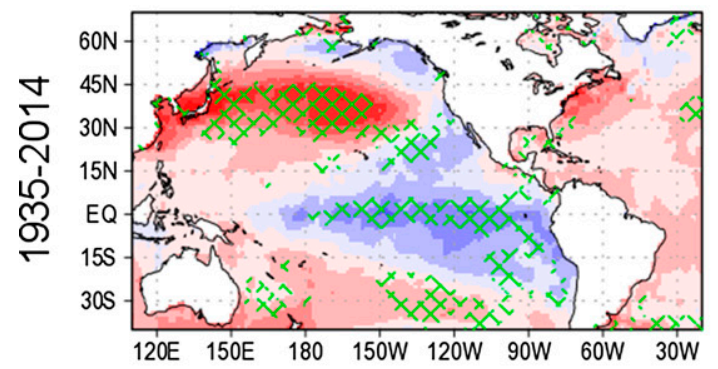

(b) ENSO (-)

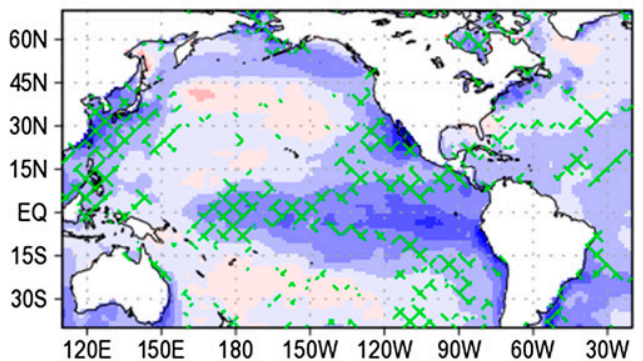

(d) ENSO (-)

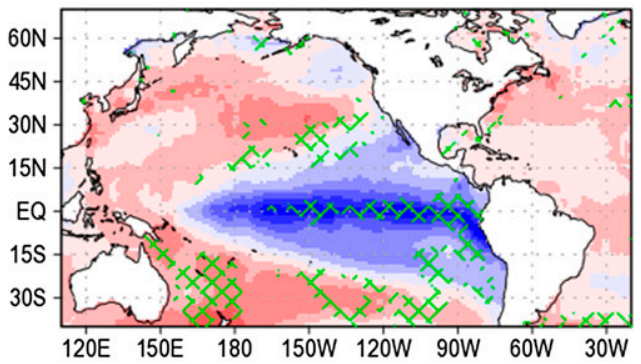

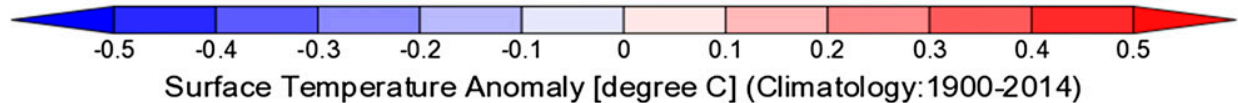

(e) PDO (-)

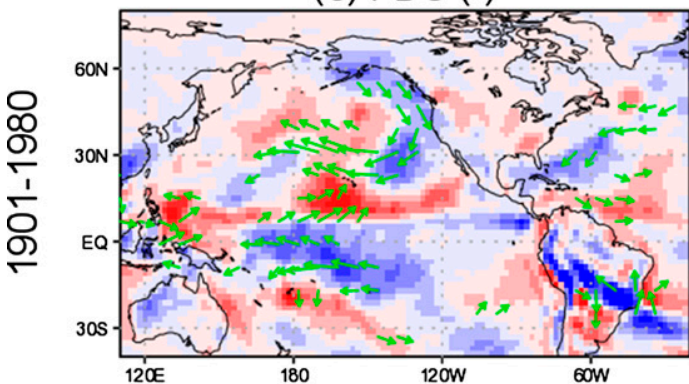

(g) PDO (-)

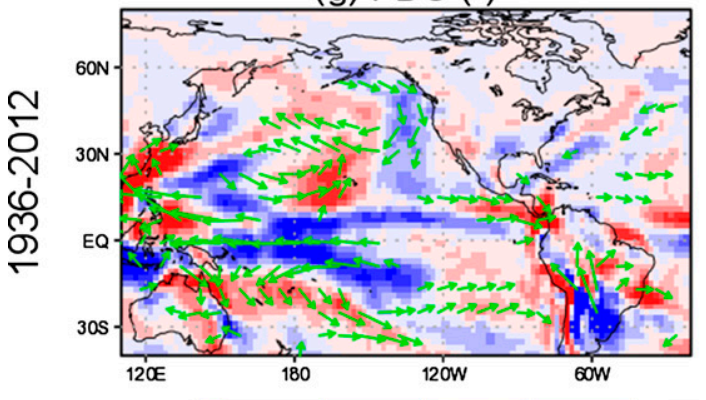

\begin{tabular}{llll|l|l|l}
-1 & -0.8 & -0.6 & -0.4 & -0.2
\end{tabular}

Moisture Convergence Anomaly [mm/day] (PDO(-)/ENSO(-) - Clim )

(f) ENSO (-)

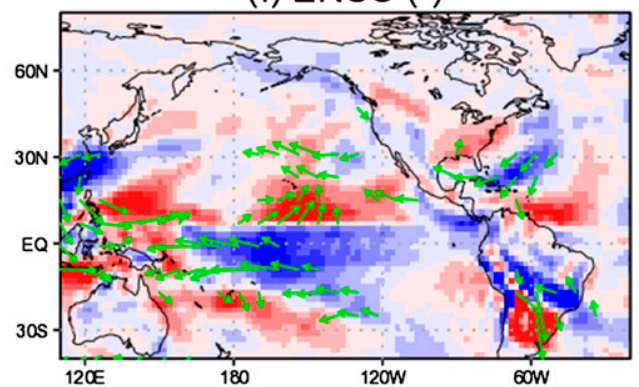

(h) ENSO (-)

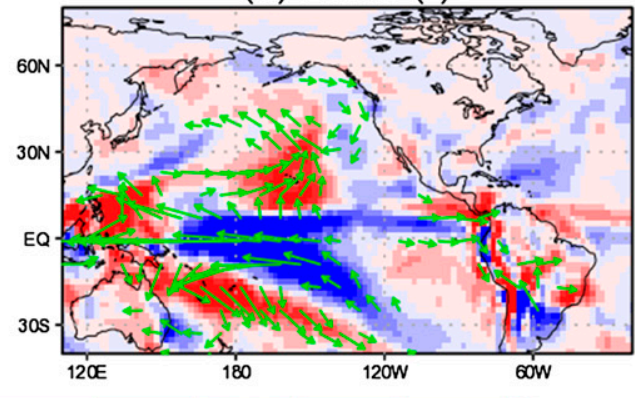

FIG. 4. Multidecadal changes in the Pacific Ocean and their associations with moisture transport and convergences. Composite spatial distributions for annually averaged sea surface temperature anomalies during PDO $(-)$ and ENSO(-) of the periods (a),(b) 1900-79 and (c),(d) 1935-2014. Significant levels are shown as green cross hatching in (a)-(d) for the $95 \%$ confidence level. Composite spatial distributions for wintertime vertically integrated moisture transport [vectors; $\mathrm{kg}(\mathrm{m} \mathrm{s})^{-1}$ ] and convergence anomalies during the anomalies during PDO $(-)$ and $\operatorname{ENSO}(-)$ of the periods (e),(f) 1901-80 and (g),(h) 1936-2012. 

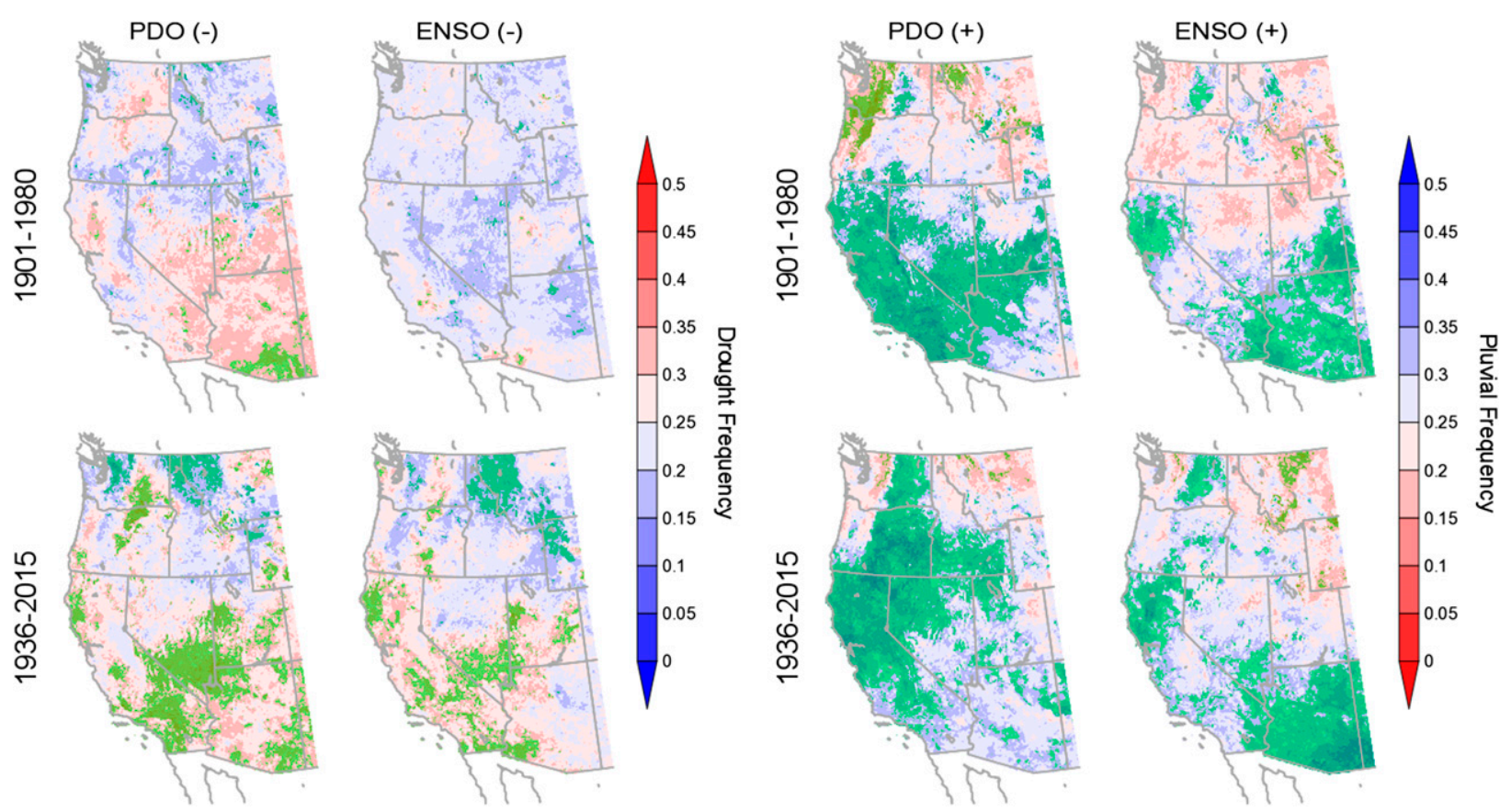

FIG. 5. Multidecadal changes in winter (left) drought and (right) pluvial risk over the western United States for different phases of SST variations in the Pacific Ocean. Green shaded areas over blue (red) shaded areas represent areas with higher drought and pluvial frequency than 0.25 based on the conditional posterior distributions with degree of belief equal to or greater than $90 \%$ (smaller than $10 \%$ ).

of drought moderately between the first 80 and last 80 years (only $6 \%$ of the region; not shown). This suggests that the spatial patterns of the influence of $\mathrm{PDO}(-)$ and $\mathrm{ENSO}(-)$ and their impacts on California winter drought have changed at multidecadal scale. The positive phases of the PDO and ENSO are associated with increased winter pluvial risk over the whole of California and Northern California, respectively. Changes in pluvial risk between the two periods (1901-80 and 1936-2015) are significant but for a smaller area relative to the changes in drought risk $(7 \%-8 \%$ of the region shows a significant increase in pluvial risk and no areas show a significant decrease; Fig. 3).

\section{b. Potential mechanisms of changes in California drought and pluvial risk}

Composite annual SST anomaly patterns for the last 80 years show that the surface temperature gradient between the north-central and equatorial Pacific has become larger for both $\mathrm{PDO}(-)$ and $\mathrm{ENSO}(-)$. Specifically, warm SST anomalies during the negative phase of the PDO have become significantly warmer over the north-central Pacific compared to the first 80 years (based on the Student's $t$ test at a significance level of 0.05 ; darker red and hatched area in Fig. 4c). Over the same period, cool SST anomalies during the negative phase of ENSO have become cooler over the tropical Pacific with statistically significant changes over the equatorial Pacific region. Although global warming contributed to the emergence of positive sea surface temperature anomalies over most of the Pacific Ocean during this time period, the magnitude of these anomalies are relatively weak compared to the changes in the anomalies over the regions related to the PDO and ENSO (see Fig. S3 in the supplementary material).

The changes in the SST anomaly patterns are associated with changes in large-scale atmospheric circulation over tropical and extratropical regions of the Pacific (Fig. 4). During the last 80 years, weaker northwesterly winds over the North Pacific have occurred during $\mathrm{PDO}(-)$, resulting in less southeastward moisture transport. Similarly, stronger easterly winds over the equatorial Pacific have occurred during $\operatorname{ENSO}(-)$, resulting in greater westward moisture transport. These moisture transport patterns reduce precipitation over California more than normal. Conversely, this led to more moisture convergence (above-normal precipitation) over the western Pacific and southeastern Asia. This mechanism is consistent with idealized model experiments. Over the extratropical Pacific region, cold and warm SST anomalies (above two standard deviations) over the tropical and north-central Pacific via air-sea interactions (Lau and Nath 1996) induced high pressure in the midtroposphere during $\mathrm{PDO}(-)$, which caused less moisture transport equatorward from the north-central Pacific. These anomalies were stronger during 1934-2011 compared to $1901-80$ (see Fig. S4 in the supplementary material), 

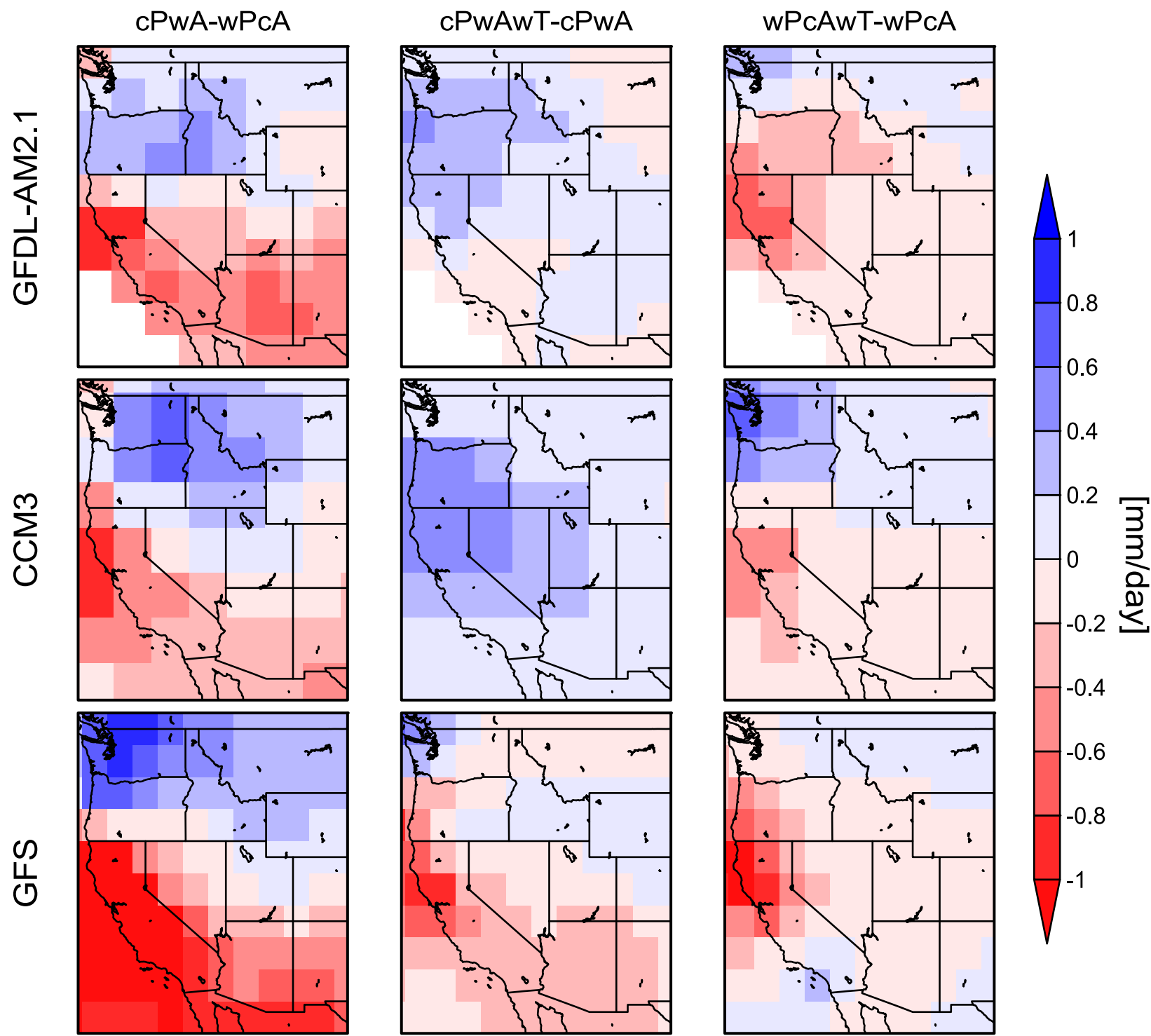

FIG. 6. Idealized SST experiment runs of global climate models from the CLIVAR Drought Working Group initiative: (top) GFDL AM2.1, (middle) CCM3, and (bottom) GFS. Four different SST experiments from three GCMs are represented: cold Pacific and warm Atlantic SST anomalies without and with long-term global warming (cPwA and cPwAwT, respectively) and warm Pacific and cold Atlantic SST anomalies without and with long-term global warming (wPcA and wPcAwT, respectively). GFDL AM2.1 and CCM3 are 50-yr simulations, and GFS is a 36-yr simulation. The differences of winter precipitation are computed from the average over the full period from an individual experiment run.

thus increasing the risk of drought during $\mathrm{PDO}(-)$ and $\operatorname{ENSO}(-)$. For pluvial events, $\mathrm{PDO}(+)$ and $\operatorname{ENSO}(+)$ show statistically significant positive SST anomalies over a broader region of the tropical Pacific during the last 80 years (see Fig. S5 in the supplementary material) compared to $\mathrm{PDO}(-)$ and $\mathrm{ENSO}(-)$. These anomalies drove moisture transport over the tropical region in the opposite direction and thus more pluvial events over Northern California. Examination of changes in risk over the broader region of the western United States (Fig. 5) shows that decreased moisture transport over
Southern California and increased moisture transport over Northern California are embedded in an overall northward shift in pluvial risk and southward shift in drought risk.

To test whether climate change has played a role in changing the risk of California winter droughts and pluvials, we compared idealized SST experiment simulations of three global climate models and without global SST increasing trend as one of the results due to climate change (Fig. 6). Without the SST increasing trend, the model experiments show that cold SST 
anomalies over the Pacific and warm SST anomalies over the North Atlantic [similar to a combination of $\operatorname{PDO}(-)$, $\mathrm{AMO}(+)$, and $\operatorname{ENSO}(-)]$ are associated with reduced precipitation over the U.S. Southwest, indicating that the models can reproduce the observed relationships between oceanic states and California precipitation variability. With the global SST increasing trend, the models show decreases in the precipitation deficit induced by cold Pacific and warm Atlantic SSTs and decreases in precipitation surplus induced by warm Pacific and cold Atlantic SSTs, suggesting an overall weakening of the intensity of SST-driven wintertime extremes. There is some disagreement of the GCM responses to global SST warming trends in terms of the spatial patterns over California, but the models show a fairly consistent response (e.g., reduction of precipitation deficits) to the warming trends at regional scale. Based on available data for a single climate model with a historic climate simulation, the global SST increasing trend has slightly offset increases in drought (pluvial) risk induced by cold (warm) Pacific SSTs, but not significantly (see Fig. S6 in the supplementary material).

\section{Conclusions and outlook for California drought risk}

The longevity and severity of the 2011-15 California winter drought have implicated climate change as having played a role. However, this drought should be viewed in the context of multidecadal climate variability and in particular changes in oceanic states associated with ENSO and the PDO that provide ideal conditions for drought. Idealized model experiments suggest that the increase in drought and pluvial risk over much of California during favorable oceanic phases is mainly due to natural variability, although global warming may have offset these increases somewhat.

Since the winter of 2014/15 ENSO and PDO have transitioned to their positive phases, which are associated with an increase in wintertime pluvial risk over California. Climate model predictions indicate that the positive ENSO phase will persist through 2016 (Kirtman et al. 2014) with the expectation of a precipitation surplus in the winter of 2015/16, which might help alleviate the current drought. However, decadal forecasts initialized with observed wind stresses (Thoma et al. 2015) predict that the current negative PDO conditions [also associated with the global warming hiatus (Delworth et al. 2015)] will persist until the mid-2020s, suggesting that the long-term risk of drought over California will continue to be elevated, with the occurrence of individual drought events depending on the frequency of $\operatorname{ENSO}(-)$ (La Niña) events.
Acknowledgments. We are grateful to Dr. Ming Pan and Dr. Kirsten Findell for sharing the simulated snow water equivalent data and the idealized SST experiment runs, respectively. This work was funded by the NOAA OAR Climate Program Office (NA14OAR4310218, NA10OAR4310130, and NA11OAR 4310097 for JK and JS).

\section{REFERENCES}

Barnett, T. P., and Coauthors, 2008: Human-induced changes in the hydrology of the western United States. Science, 319, 10801083, doi:10.1126/science.1152538.

Bond, N. A., M. F. Cronin, and N. Mantua, 2015: Causes and impacts of the 2014 warm anomaly in the NE Pacific. Geophys. Res. Lett., 42, 3414-3420, doi:10.1002/2015GL063306.

Compo, G. P., and Coauthors, 2011: The Twentieth Century Reanalysis Project. Quart. J. Roy. Meteor. Soc., 137, 1-28, doi:10.1002/qj.776.

Cook, B. I., J. E. Smerdon, R. Seager, and E. R. Cook, 2014: Pancontinental droughts in North America over the last millennium. J. Climate, 27, 383-397, doi:10.1175/JCLI-D-13-00100.1.

Daly, C., and Coauthors, 2008: Physiographically sensitive mapping of climatological temperature and precipitation across the conterminous United States. Int. J. Climatol., 28, 20312064, doi:10.1002/joc.1688.

Damsleth, E., and A. H. El-Shaarawi, 1988: Estimation of autocorrelation in a binary time series. Stoch. Hydrol. Hydraul., 2, 61-72, doi:10.1007/BF01544195.

Delworth, T. L., and Coauthors, 2015: A link between the hiatus in global warming and North American drought. J. Climate, 28, 3834-3845, doi:10.1175/JCLI-D-14-00616.1.

Dixon, L. S., N. Y. Moore, and E. M. Pint, 1996: Drought management policies and economic effects in urban areas of California, 1987-1992. RAND Tech. Rep., 156 pp. [Available online https://www.rand.org/content/dam/rand/pubs/ monograph_reports/2007/MR813.pdf.]

Famiglietti, J. S., and Coauthors, 2011: Satellite measure recent rates of groundwater depletion in California's Central Valley. Geophys. Res. Lett., 38, L03403, doi:10.1029/2010GL046442.

Findell, K. L., and T. L. Delworth, 2010: Impact of common sea surface temperature anomalies on global drought and pluvial frequency. J. Climate, 23, 485-503, doi:10.1175/ 2009JCLI3153.1.

Gimeno, L., and Coauthors, 2012: Oceanic and terrestrial sources of continental precipitation. Rev. Geophys., 50, RG4003, doi:10.1029/2012RG000389.

Grantham, T. E., and J. H. Viers, 2014: 100 years of California's water rights system: Patterns, trends, and uncertainty. Environ. Res. Lett., 9, 084012, doi:10.1088/1748-9326/9/8/084012.

Kam, J., J. Sheffield, and E. F. Wood, 2014a: A multiscale analysis of drought and pluvial mechanisms for the southeastern United States. J. Geophys. Res. Atmos., 119, 7348-7367, doi:10.1002/2014JD021453.

,-- , and,$- 2014 \mathrm{~b}$ : Changes in drought risk over the contiguous United States (1901-2012): The influence of the Pacific and Atlantic Oceans. Geophys. Res. Lett., 41, 58975903, doi:10.1002/2014GL060973.

_ T. T. Knutson, F. Zeng, and A. T. Wittenberg, 2015: Record annual-mean warmth over Europe, the northeast Pacific, and the northwest Atlantic during 2014: Assessment of 
anthropogenic influence [in "Explaining Extreme Events of 2014 from a Climate Perspective"]. Bull. Amer. Meteor. Soc., 96 (12), S61-S65, doi:10.1175/BAMS-D-15-00101.1.

Kirtman, B. P., and Coauthors, 2014: The North American multimodel ensemble: Phase-1 seasonal-to-interannual prediction; phase-2 toward developing intraseasonal prediction. Bull. Amer. Meteor. Soc., 95, 585-601, doi:10.1175/BAMS-D-12-00050.1.

Lau, N.-C., and M. J. Nath, 1996: The role of the "atmospheric bridge" in linking tropical Pacific ENSO events to extratropical SST anomalies. J. Climate, 9, 2036-2057, doi:10.1175/ 1520-0442(1996)009<2036:TROTBI >2.0.CO;2.

Mao, Y., B. Nijssen, and D. P. Lettenmaier, 2015: Is climate change implicated in the 2013-2014 California drought? A hydrologic perspective. Geophys. Res. Lett., 42, 2805-2813, doi:10.1002/ 2015 GL063456.

McCabe, G. J., M. A. Palecki, and J. L. Betancourt, 2004: Pacific and Atlantic Ocean influences on multidecadal drought frequency in the United States. Proc. Natl. Acad. Sci. USA, 101, 4136-4141, doi:10.1073/pnas.0306738101.

Mo, K. C., J. Schemm, and S. Yoo, 2009: Influence of ENSO and the Atlantic multidecadal oscillation on drought over the United States. J. Climate, 22, 5962-5982, doi:10.1175/ 2009JCLI2966.1.

Namias, J., 1978: Recent drought in California and western Europe. Rev. Geophys., 16, 435-458, doi:10.1029/RG016i003p00435.

Pan, M., and Coauthors, 2003: Snow process modeling in the North America land data assimilation system (NLDAS): 2. Evaluation of model simulated snow water equivalent. J. Geophys. Res., 108, 8850, doi:10.1029/2003JD003994.

Rayner, N. A., and Coauthors, 2003: Global analyses of sea surface temperature, sea ice, and night marine air temperature since the late nineteenth century. J. Geophys. Res., 108, 4407, doi:10.1029/2002JD002670.

Schonher, T., and S. E. Nicholson, 1989: The relationship between California rainfall and ENSO events. J. Climate, 2, 1258-1269, doi:10.1175/1520-0442(1989)002<1258:TRBCRA > 2.0.CO;2.

Schubert, S. D., M. J. Suarez, P. J. Pegion, R. D. Koster, and J. T. Bacmeister, 2004: On the cause of the 1930s dust bowl. Science, 303, 1855-1859, doi:10.1126/science.1095048.

— , and Coauthors, 2009: A U.S. CLIVAR project to assess and compare the responses of global climate models to droughtrelated SST forcing patterns: Overview and results. J. Climate, 22, 5251-5272, doi:10.1175/2009JCLI3060.1.

Seager, R., and Coauthors, 2007: Model projections of an imminent transition to a more arid climate in southwestern North America. Science, 316, 1181-1184, doi:10.1126/ science.1139601.

-, M. Hoerling, S. Schubert, H. Wang, B. Lyon, A. Kumar, J. Nakamura, and N. Henderson, 2015: Causes of the 2011-14 California drought. J. Climate, 28, 6997-7024, doi:10.1175/ JCLI-D-14-00860.1.

Stine, S., 1994: Extreme and persistent drought in California and Patagonia during mediaeval time. Nature, 369, 546-549, doi:10.1038/369546a0.

Thoma, M., R. J. Greatbatch, C. Kadow, and R. Gerdes, 2015: Decadal hindcasts initialized using observed surface wind stress: Evaluation and prediction out to 2024. Geophys. Res. Lett., 42, 6454-6461, doi:10.1002/2015GL064833.

Wang, H., and S. Schubert, 2014: Causes of the extreme dry conditions over California during early 2013 [in "Explaining Extreme Events of 2013 from a Climate Perspective"]. Bull. Amer. Meteor. Soc., 95 (9), S7-S11. 